PSICOLOGÍA

IBEROAMERICANA
Psicología Iberoamericana ISSN: 1405-0943

revista.psicologia@ibero.mx

Universidad Iberoamericana, Ciudad de México México

\title{
Reflexiones sobre los retos de la investigación en tiempos de emergencias
}

Polanco Hernández, Graciela

Reflexiones sobre los retos de la investigación en tiempos de emergencias

Psicología Iberoamericana, vol. 28, núm. 2, 2020

Universidad Iberoamericana, Ciudad de México, México

Disponible en: http://www.redalyc.org/articulo.oa?id=133964928003

Esta obra está bajo una Licencia Creative Commons Atribución 4.0 Internacional.

Esta obra está bajo una Licencia Creative Commons Atribución 4.0 Internacional. 


\title{
Reflexiones sobre los retos de la investigación en tiempos de emergencias
}

\author{
Graciela Polanco Hernández graciela.polanco@ibero.mx \\ Universidad Iberoamericana, Ciudad de México, México \\ http://orcid.org/0000-0003-1661-7518
}

Psicología Iberoamericana, vol. 28, núm. 2,2020

Universidad Iberoamericana, Ciudad de México, México

Redalyc: http://www.redalyc.org/ articulo.oa?id=133964928003

Esta obra está bajo una Licencia Creative Commons Atribución 4.0 Internacional. CC BY
En 2020, ante la inesperada pandemia de COVID-19, se han tenido que tomar medidas de confinamiento social, situación que vino a modificar la dinámica y el estilo de vida de la población a nivel mundial; aspectos de gran importancia a considerar al realizar investigación sobre salud mental y comportamiento.

Por su alto nivel de contagio, esta emergencia de salud nos obligó a migrar de la vida universitaria tradicional y presencial al campus virtual, manteniendo la misma comunicación y sentido de comunidad, acompañamiento a nuestros estudiantes. Este entorno nos ha puesto a prueba como personas, docentes e investigadores para ser más flexibles, creativos, dispuestos y sensibles y para impactar en el estilo educativo, de investigación e intervención sin perder el sentido social.

Realizar investigación durante una emergencia tiene retos importantes a considerar, debido a la situación vulnerable que viven las personas participantes como son los afectados, los primeros intervinientes, el personal de salud, la comunidad y los reporteros de los medios de comunicación. Esta población afectada es atendida por una diversidad de Organismos internacionales, Instituciones gubernamentales y ONG involucradas en la respuesta.

Como investigador es importante conocer y considerar todos los protocolos oficiales y a los actores involucrados para solicitar el acceso, responder y presentar resultados.

Ante cualquier escenario durante una emergencia, realizar trabajo de campo presencial es de alto riesgo por el difícil acceso y el posible contagio; es importante también tener presente el estado físico y emocional de todos los actores participantes. Por lo que se recomienda hacer investigaciones con propósitos específicos, de alta relevancia, pero sin dejar de lado el aporte a la ciencia.

Otros retos a los que nos enfrentamos al realizar investigación durante una emergencia es el poco tiempo, la presión para actuar, la tensión entre la investigación y la respuesta de emergencia inmediata ante la gran necesidad. Este es el momento de realizar investigación colaborativa, es decir, generar redes profesionales y de trabajo interdisciplinario.

Por todo lo anterior, es importante tomar en cuenta cuáles temáticas y qué tipo de estudios se necesitan en ese momento, para 
buscar instituciones financieras nacionales e internacionales que estén interesadas, sean empáticas y apoyen investigaciones en las áreas de salud y del comportamiento social con el fin de desarrollar y promover políticas públicas.

Además, no podemos dejar de lado la importante y polémica dimensión de la ética al realizar investigación durante las emergencias. La ética no sólo se refiere al comportamiento de las personas directamente involucradas en la investigación, sino también, se refiere a los conflictos y dilemas entre los valores y principios éticos en juego. León (2012) considera que un desastre de origen natural no puede considerarse una situación moral o inmoral, justa o injusta; sin embargo, sus consecuencias sí se pueden tratar de esta manera porque son responsables en un grado secundario, en la medida en que su acontecer o sus efectos pudieron ser evitados o disminuidos. Finalmente, la solidaridad nos pone en el lugar del otro y nos mueve por compasión.

Es frecuente escuchar que la ética de la investigación se refiere únicamente al protocolo de revisión ética que involucra a personas, sin considerarla como una dimensión mucho más amplia. Por tal razón, como investigadores también debemos reflexionar, sobre:

Cómo incluir de forma significativa las necesidades de los afectados en un estudio apropiado y ético ante los dificiles contextos en los que se realiza, cuando muchas de las decisiones se toman a nivel de la politica o nivel económico, como es el caso de para qué y cuándo se deben utilizar los fondos para prevención y atención de emergencias.

También se debe considerar cómo garantizar que se prioricen los aspectos éticos en un contexto de pandemia donde lo urgente es dar respuesta. Las investigaciones realizadas durante las emergencias pueden plantear problemas éticos particularmente complejos y desafiantes, entre éstos está el protocolo para ser autorizado por Comités de Ética de la investigación, donde el tiempo es un factor muy importante. Así como también la dificultad de obtener firmada la carta de consentimiento informado por parte de los participantes ante un estado de vulnerabilidad física y emocional.

Como anteriormente se mencionó, realizar una investigación durante una emergencia es una gran oportunidad de compartir y utilizar éticamente la información recolectada entre los investigadores y las instituciones participantes. Es importante considerar cómo colaborar con los investigadores que están en trabajo de campo para que aborden los dilemas éticos que se les presentan.

Todos estos factores que se suman a los riesgos de la investigación que, por muy bien intencionada que sea, podrían también causar daños directos y no ser considerados debido al etnocentrismo del investigador. Sin embargo, también puede haber riesgos al no realizarla.

Para finalizar, es importante nunca dejar de considerar que la investigación es por y para la sociedad, por un bien común y socialmente ética para mejorar la preparación y la respuesta en situaciones de emergencia actuales y futuras. 


\section{Referencias}

León, F. J. (2012). Después de un terremoto. Bioética en situaciones de catástrofe. Revista Médica de Chile, 140(1), 108-112. 